\title{
TRATAMENTO CONTRA O ADENOCARCINOMA MAMÁRIO HUMANO POR MEIO DA TERAPIA FOTODINÂMICA UTILIZANDO O AZUL DE METILENO
}

\author{
Bianca Silva Prado ${ }^{1}$ \\ Maiara Lima Castilho \\ Lucas Pereira Leite ${ }^{3}$ \\ Leandro Raniero ${ }^{4}$
}

Resumo: A terapia fotodinâmica (TFD) é um método alternativo para o tratamento contra o câncer, possui baixa toxicidade sistêmica podendo ter ação localizada. O seu mecanismo de ação é baseado na combinação de um fotossensibilizador, luz e o oxigênio presente nos tecidos. Com o trabalho avaliou-se a ação do fotossensibilizador azul de metileno (AM) no tratamento contra o adenocarciona mamário humano por meio da TFD. As células foram cultivadas utilizando o meio de cultura Leibovitz's complementado com $10 \%$ de soro fetal bovino e mantidas em estufa para crescimento. O tratamento via TFD foi realizado utilizando o fotossensibilizador AM em três diferentes concentrações sendo irradiadas com LEDs $660 \mathrm{~nm}$. A viabilidade celular foi realizada utilizando o método de exclusão Azul de Tripan. Os resultados obtidos sugerem que o azul de metileno apresenta grande potencial, pois possibilitou uma redução da taxa de viabilidade celular sob irradiação e baixa citotoxicidade quando não irradiando.

Palavras-chave: Terapia Fotodinâmica; Azul de metileno; Câncer de mama.

\footnotetext{
${ }^{1}$ Biomedicina/Universidade do Vale do Paraíba, Brasil. E-mail: biancasilvaprado@hotmail.com.

2 Engenharia Biomédica/Universidade do Vale do Paraíba, Brasil. E-mail: maiara.engbiomedica@gmail.com.

3 Biomedicina/Universidade do Vale do Paraíba, Brasil. E-mail: lucaslleitepereira@gmail.com.

${ }^{4}$ Física/Universidade do Vale do Paraíba, Brasil. E-mail: Iraniero@univap.br.
} 